\title{
Optimization of Culture Condition for Enhanced Decolorization of Direct blue Dye by Aspergillus flavus and Penicillium canescens
}

\author{
Mohamed A. Hefnawy, Mohamed M. Gharieb, Mohamed T. Shaaban and Azza M. Soliman \\ Botany Department, Faculty of Science, Menoufia University, Egypt.
}

\begin{tabular}{l} 
ARTICLE INFO \\
\hline Article history: \\
Received on: $10 / 11 / 2016$ \\
Accepted on: $11 / 12 / 2016$ \\
Available online: $27 / 02 / 2017$ \\
\hline $\begin{array}{l}\text { Key words: } \\
\text { Penicillium canescens, Direct } \\
\text { blue dye, Decolorization. }\end{array}$
\end{tabular}

blue dye, Decolorization.

\begin{abstract}
Six fungal species were isolated from Egyptian soil and identified as Aspergillus flavus, Aspergillus niger, Penicillium canescens, Penicillium crustosum, Penicillium sp. and Fusarium sp. and were tested for their decolorization activity of direct blue dye (DB). Aspergillus flavus and Penicillium canescens were the best active fungal species for decolorization of direct blue dye. The optimum conditions for direct blue dye decolorization by both fungi grown on Czapek's Dox liquid medium were at a concentration of $0.01 \%$ Direct blue dye, sucrose as a carbon source, $\mathrm{NaNO}_{3}$ as a nitrogen source, incubation temperature $30^{\circ} \mathrm{C}$ and $35^{\circ} \mathrm{C}$ and $\mathrm{pH} \mathrm{4,} 5$ for both fungi respectively and incubation time for 7 days. Addition of some metals $(\mathrm{Ca}, \mathrm{Ni}, \mathrm{Co})$ to the growth medium exhibited little effect on dye decolorization. Whereas, $\mathrm{Cu}(2+)$ highly inhibited dye decolorization by both fungi.
\end{abstract}

\section{INTRODUCTION}

The waste disposal problem will cause more threats to the environment unless new technologies for bioremediation of the toxic compounds are developed to reduce its detrimental effects on the environment in general and in cultivated land in particular. Approximately 50\% of the dyes are released in the industrial effluents (Zollinger, 1991). Colored industrial effluents from the dyeing industries represent major environmental problems. The strong color of discharged dyes even at very small concentrations has a huge impact on the aquatic environment caused by its turbidity and high pollution strength; in addition toxic degradation products can be formed. Dye wastewater discharged from textile and dyestuff industries have to be treated due to their impact on water bodies and growing public concern over their toxicity and carcinogenicity. Many different and complicated molecular structures of dyes make dye wastewater

\footnotetext{
* Corresponding Author

E-mail: ahmedabdulhafezhamad @ yahoo.com
}

difficult to be treated by conventional biological and physicochemical processes. Therefore, innovative treatment technologies need to be investigated. Decolorization of dye wastewater by fungal metabolic activities is the subject of many studies (Sathiya et al., 2007). Azo dyes represent half of the dyes used in the textile industry and, as a consequence, a relevant problem of pollution related to the release of these products in the environment is taking place (Shrivastava, 2011). The azo groups are generally connected to benzene and naphthalene rings, but can also be attached to aromatic heterocyclic or enolizable aliphatic groups (Zollinger, 2003). The azo linkage is considered the most labile portion of an azo dye. The linkage easily undergoes enzymatic breakdown, but thermal or photochemical breakdown may also take place. Degradation of azo dyes can be obtained by reduction or by oxidation. The reduction releases the colorless component amines. There are various methods for the treatment of textile wastewater for the removal of dye. These broadly fall into three categories: Physical, Chemical and Biological. These methods have earlier been extensively reviewed (Hao et al., 2000; Robinson et al., 2001; Forgacs et al., 2004; Joshi et al., 2004). 
Fungi have proved to be suitable organisms for the treatment of textile effluent and dye removal. The fungal mycelia have an additive advantage over single cell organisms by solubilizing the insoluble substrates by producing extracellular enzymes. Due to an increased cell-to-surface ratio, fungi have a greater physical and enzymatic contact with the environment. The extra-cellular nature of the fungal enzymes is also advantageous in tolerating high concentrations of the toxicants. Many genera of fungi have been employed for the dye decolorization either in living or dead form (Kaushik and Malik, 2009). Ramalingam et al. (2010) investigated the degradation ability of mixed fungal cultures (Tricoderma sp. and Aspergillus flavus) for coomassie brilliant blue.

They found that dye decolorization was achieved by metabolism rather than by adsorption and these fungi could effectively by used in development of alternative and eco-friendly method for removal and degradation of textile dyes. Phanerochaete chrysosporium was found to be able to decolorize and mineralize direct blue " 80 " dye up to $99.6 \%$ and textile waste effluent up to $97.7 \%$ (Shinkafi et al. 2015). Yang et al. (2016) also showed the valuable capability of freshwater fungi for the treatment of dye-containing effluents. Dye decolorization with microorganism is low cost effective and environmentally friend and the only way for ultimate controlling of pollution generated by textile and dye stuff industries (Ponraj et al., 2011). The purpose of this study is to evaluate the activity of some fungal species (Egyptian isolates) for decolorization of Direct blue dye and characterize their decolorization capacity under various conditions.

\section{MATERIALS AND METHODS}

\section{Chemicals}

All chemicals used were of analytical grade.

Dye

The Direct blue (DB) dye was obtained from Quesna Dyers Company, Quesna, Minoufiya Governorate and is routinely used in the dying process of cotton fibers. It belongs to the azo class (Fig.1).

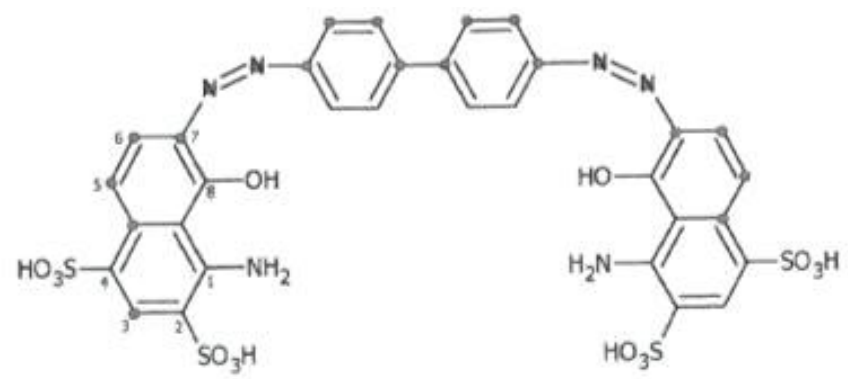

Fig. 1: Chemical structure of direct blue dye.

Media

1- The growth medium Czapek's Dox Agar (CDA) consists of (g/L) $\mathrm{NaNO}_{3}, 2$; Sucrose, 30; $\mathrm{KH}_{2} \mathrm{PO}_{4}, 1 ; \mathrm{KCl}, 0.5$;
MgSO $4.7 \mathrm{H}_{2} \mathrm{O}, 0.5$; FeSO $4.7 \mathrm{H}_{2} \mathrm{O}$, traces; yeast extract, 2 and the $\mathrm{pH}$ was adjusted to 6.5 .

2- Also the organisms were cultured on Potato dextrose agar (PDA) medium containing $(\mathrm{g} / \mathrm{L})$ potato extract (extracted from $200 \mathrm{~g}$ potato); dextrose, 20; agar, 15 and the $\mathrm{pH}$ was adjusted to 6.5 .

\section{Isolation of dye decolorizing fungi:}

A garden clay soil and wood chips were mixed into a ratio of (1:1) and their moisture content was adjusted to $70 \%$ by adding sterile distilled water. The mixture was placed in a polyethelene bags. The bags were incubated at $28 \pm 2{ }^{\circ} \mathrm{C}$ for 4 weeks. Soil plate technique according to Warcup (1950) was used to isolate different fungal species on PDA medium. The number of colony and fungal species frequency was calculated. The fungal species were subcultured for purification and maintained on slants of PDA medium.

\section{Identification of the isolated fungal species:}

The isolated fungal species were identified at the Regional Center for Mycology and Biotechnology at Al- Azhar University Cairo, Egypt.

\section{Testing the isolated fungi for decolorization of direct blue dye on solid agar medium}

A disc of $6 \mathrm{~mm}$ of fungal mycelium was placed on to the center of Petri-dishes $(90 \mathrm{~mm})$ containing $10 \mathrm{ml}$ of solid PDA medium supplemented with Direct blue dye with a concentration of $(0.01 \%)$. The plates were incubated at $28 \pm 2{ }^{\circ} \mathrm{C}$ for 7 days. Triplicate sets of plates were used for each fungal species. The decolorization zone and colony diameter were measured (Machado et al., 2005).

\section{Decolorization of Direct blue dye in liquid medium:}

A disc $(6 \mathrm{~mm})$ of fugal mycelium was transferred to 250 $\mathrm{ml}$ Erlenmeyer flasks containing $50 \mathrm{ml}$ of autoclaved Czapek's Dox medium, supplemented with $100 \mathrm{mg} / \mathrm{L}$ of direct blue dye. The flasks were incubated at $28 \pm 2{ }^{\circ} \mathrm{C}$ for 7 days. Triplicate sets of flasks were used for each fungal species. Non inoculated culture medium was used as control. Mycelia were collected by filtration and the supernatant was analyzed for dye decolorization. Dye disappearance was determined spectrophotometrically by monitoring the absorbance at the maximum wave length for dye (610 $\mathrm{nm}$ for direct blue dye). The decolorization activity is expressed as the color reduction percentage $(\% \mathrm{R})$ and calculated according to Casieri et al. (2008) as follows:

$$
\% \mathrm{R}=100\left(\mathrm{~A}_{0}-\mathrm{A}_{\mathrm{t}}\right) / \mathrm{A}_{0}
$$

Where $A_{0}$ is the absorbance value of the initial dye concentration and $A_{t}$ is the absorbance value of the final dye concentration at time $t$. The best fungal species for dye decolorization were used for further studies. 
Factors affecting growth and decolorization

Effect of different direct blue dye concentrations on decolorization by Aspergillus flavus and Penicillium canescens in liquid media

Aspergillus flavus and Penicillium canescens were grown on Czapek's Dox liquid medium supplemented with different concentrations of direct blue dye (10, 20, 50, 100, $200 \mathrm{mg} / \mathrm{L})$. The fungi were grown in 250 Erlenmeyer flask containing $50 \mathrm{ml}$ of the medium and inoculated with $6 \mathrm{~mm}$ disc of the fungal mycelium.

The flasks were incubated at $28 \pm 2^{\circ} \mathrm{C}$ for 7 days. Triplicates sets of flasks were used for each fungus and dye concentration. After the incubation period, the mycelium was harvested, washed and dried at $85{ }^{\circ} \mathrm{C}$ until constant weight. The dry mass was determined and the percentage of dye decolorization was also determined as mentioned before.

\section{Effect of different incubation temperatures of the culture medium on the decolorization of direct blue dye}

The experiment was conducted as mentioned above, each flask containing $50 \mathrm{ml}$ of the medium with a concentration of 100 $\mathrm{mg} / \mathrm{L}$ of DB dye. The flasks were incubated at different temperatures $\left(20,25,30,35\right.$ and $\left.40^{\circ} \mathrm{C}\right)$ for 7 days and the percentage of dye decolorization was determined.

\section{Effect of different incubation periods on the decolorization of direct blue dye}

A. flavus and $P$. canescens were cultivated in $250 \mathrm{ml}$ flasks. Each flask contained $50 \mathrm{ml}$ Czapek's Dox medium supplemented with $100 \mathrm{mg} / \mathrm{L}$ Direct blue dye, and inoculated with $6 \mathrm{~mm}$ disc of the fungal mycelium. The flasks were incubated at $30 \pm 2{ }^{\circ} \mathrm{C}$ for different intervals (4, 7, 10 and 14 days). Triplicate sets of flasks were used for each fungus and different periods. The mycelium was harvested, washed and dried at $85^{\circ} \mathrm{C}$ until constant weight. The dry weight and dye decolorization was determined.

\section{Effect of different $\mathrm{pH}$ values of the culture medium on the decolorization of direct blue dye}

The experiment was conducted as mentioned above and the $\mathrm{pH}$ of the medium was monitored at different values, 3, 4, 5, 6, 7, 8 and 9 using $1.0 \mathrm{M} \mathrm{HCl}$ and $1.0 \mathrm{M} \mathrm{NaOH}$. The flasks were incubated at $30^{\circ} \mathrm{C}$ for 7 days and the percentage of decolorization was determined.

\section{Influence of different carbon sources on the decolorization of direct blue dye}

A. flavus and $P$. canescens were grown on Czapek's Dox liquid medium supplemented with different carbon sources (glucose, fructose, sucrose, maltose, lactose or starch) with a concentration of $30 \mathrm{~g} / \mathrm{L}$.

The fungi were grown in $250 \mathrm{ml}$ Erlienmeyer flask containing $50 \mathrm{ml}$ the medium supplemented with $100 \mathrm{mg} / \mathrm{L}$ Direct blue dye. The flasks were incubated at $30 \pm 2{ }^{\circ} \mathrm{C}$ for 7 days. Triplicate sets of flasks were used for each fungus and carbon source.

After the incubation period, the mycelium was harvested, washed and dried at $85^{\circ} \mathrm{C}$ until constant weight. The dry mass was determined and the percentage of decolorization was also determined as mentioned before.

\section{Influence of different nitrogen sources on the decolorization of direct blue dye}

Aspergillus flavus and Penicillium canescens were grown on Czapek s Dox liquid medium supplemented with different nitrogen sources $\left(\mathrm{NaNO}_{3}, \mathrm{NH}_{4} \mathrm{NO}_{3}, \mathrm{KNO}_{3}\right.$, urea, peptone, yeast extract) with a concentration of $2 \mathrm{~g} / \mathrm{L}$ for $\mathrm{NaNO}_{3}$, peptone and yeast extract, and equivalent nitrogen for $\mathrm{NH}_{4} \mathrm{NO}_{3}, \mathrm{KNO}_{3}$ and urea. The fungi were grown in $250 \mathrm{ml}$ Erlenmeyer flask containing $50 \mathrm{ml}$ the medium supplemented with $100 \mathrm{mg} / \mathrm{L}$ Direct blue dye.

The flasks were incubated at $30 \pm 2{ }^{\circ} \mathrm{C}$ for 7 days. Triplicates sets of flasks were used for each fungus and nitrogen source. After the incubation period, the mycelium was harvested, washed and dried at $85^{\circ} \mathrm{C}$ until constant weight. The dry mass was determined and the percentage of decolorization was also determined as mentioned before.

\section{Effect of some heavy metals on the decolorization activity of direct blue dye}

One disc of $6 \mathrm{~mm}$ fungal mycelium was transferred to $250 \mathrm{ml}$ flask containing $50 \mathrm{ml}$ of Czapek's Dox medium with a concentration of $(100 \mathrm{ppm})$ of $(\mathrm{Cu}, \mathrm{Ca}, \mathrm{Ni}$ or $\mathrm{Co})$. Two sets of the experiment were carried out in the absence and in the presence of $0.01 \%$ direct blue dye.

After the incubation period, the mycelium was harvested, washed and dried at $85^{\circ} \mathrm{C}$ until constant weight. The dry mass was determined and the percentage of decolorization was also determined as mentioned before. Each experiment was conducted in triplicates and mean values were taken.

\section{RESULTS}

Isolation of different fungal species and Agar-plate screening for decolorization of direct blue Dye

Six fungal species were isolated from a mixture of 4 weeks incubated soil samples and wood chives. These fungi were identified as Aspergillus flavus, Aspergillus niger, Penicillium canescens, Penicillium crustosum, Penicillium sp., and Fusarium $s p$. The isolated fungal species were identified at the Regional Center for Mycology and Biotechnology at Al- Azhar University Cairo, Egypt.

The obtained fungal species were tested for their decolorization activity of direct blue dye. Two fungal species Aspergillus flavus and Penicillium canescens were found to be the best isolated fungi for decolorization of direct blue dye (Fig.2). 


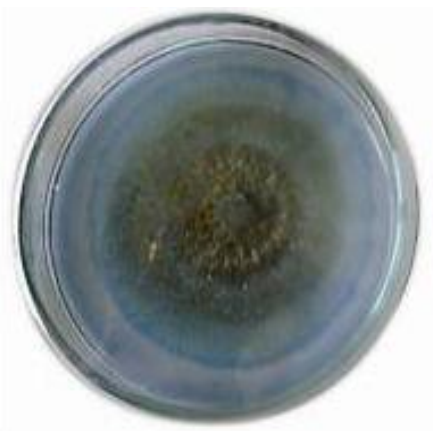

(a)

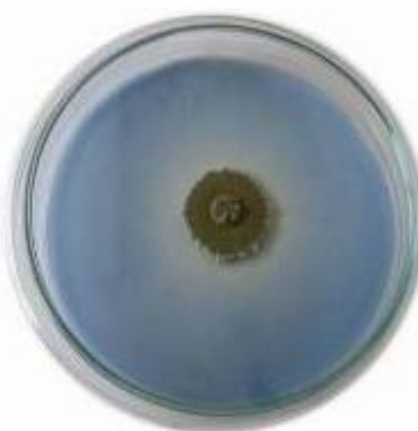

(b)
Fig. 2: Decolorization of direct blue dye by (a) Aspergillus flavus and (b) Penicillium canescens grown on PDA medium supplemented with $0.01 \%$ direct blue dye for 7 days at $28^{\circ} \mathrm{C}$.

Decolorization of direct blue dye by different isolated fungal species in solid media as a primary screening

It was found that $A$. flavus exhibited the highest decolorization activity $92 \%$, followed by $P$. canescens $89 \%$ then P. crustosum and P. sp. 87 and $85 \%$ respectively. Finally, Fusarium sp. and A. niger 75 and $60 \%$ respectively. Fig. (3) shows representative photos for the decolorization of direct blue dye by A. flavus and P. canescens.
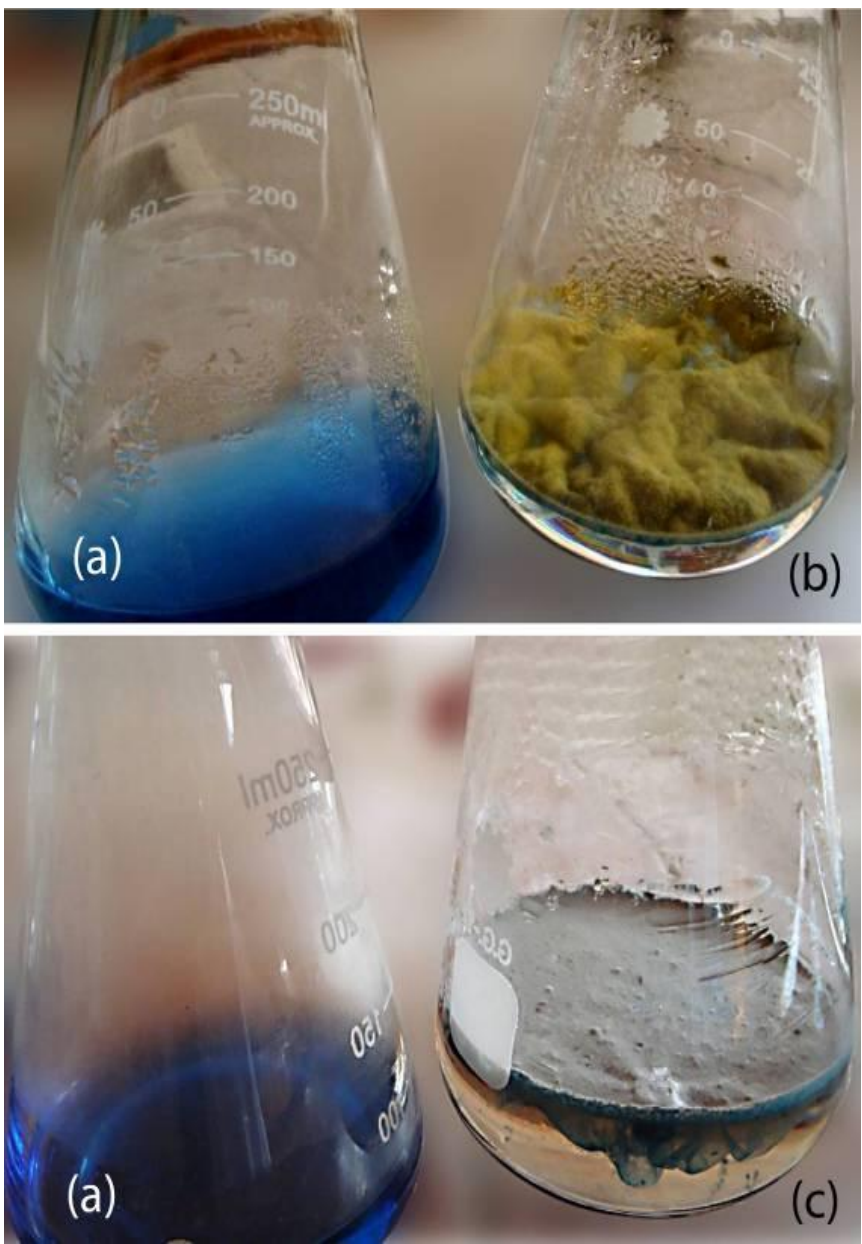

Fig. 3: Decolorization of direct blue dye (a) Control medium, (b) Aspergillus flavus and (c) Penicillium canescens grown on Czapek's Dox liquid medium supplemented with $0.01 \%$ direct blue dye for 7 days at $28^{\circ} \mathrm{C}$.

\section{Factors affecting fungal growth and dye decolorization}

Effect of different initial dye concentrations on radial growth and decolorization activity of A. flavus and P. canescens on solid medium

Radial growth of A. flavus and $P$. canescens slightly decreased by increasing dye concentrations in the growth medium (Fig. 4). At a concentration of $0.05 \%$ of DB dye, the growth of $A$. flavus reduced to approximately $27 \%$ comparing with the control medium. On the other hand, the growth of $P$. canescens was reduced to $38 \%$ at the same concentration. The best decolorization rate and percentage were obtained at $0.01 \%$ and $0.03 \%$ for $A$. flavus and $P$. canescens, respectively. It was regarded that at higher concentration of dye, the limit of decolorized zone was not determined significantly. Determination of fungal growth and decolorization ability in solid media provides unreliable data. This uncertainty due to the fact that leading edges of the mycelial mat and decolorization halo are very diffuse (Trinci, 1971) and have an irregular shapes.

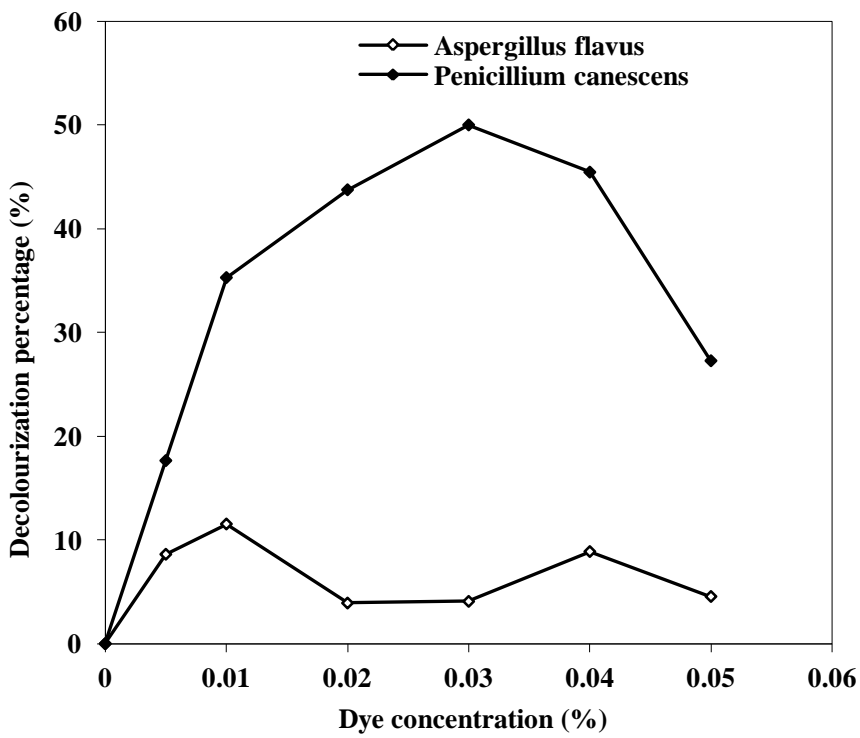

Fig. 4: Effect of different concentrations of direct blue dye on decolorization zone percentage (\%) of direct blue dye by Aspergillus flavus and Penicillium canescens grown on Potato Dextrose agar medium at $28^{\circ} \mathrm{C}$ for 7 days.

\section{Effect of initial dye concentration on dry weight and decolorization activity of Aspergillus flavus and Penicillium canescens}

The growth of Aspergillus flavus slightly increased with increasing dye concentrations in the growth medium. The dye decolorization percentage was also increased by increasing dye concentrations and reached its optimum value at $0.01 \%$ of the dye (Table 1). On the other hand the growth of Penicillium canescens was increased at lower concentrations of the dye in the growth medium up to a concentration of $0.003 \%$ and decreased above this concentration. The best dye decolorization occurred by this organism at a concentration of $0.01 \%$ and exhibited $89 \%$ decolorization value of the dye. 
Table 1. Effect of different concentrations of Direct blue dye on dry weight $(\mathrm{mg} / 50 \mathrm{ml})$ and decolourization activity of Aspergillus flavus and Penicillium canescens grown on Czapek's Dox medium at $28{ }^{\circ} \mathrm{C}$ for 7 days. Data are expressed as mean values of three replicates $\pm \mathrm{SE}$ of the mean.

\begin{tabular}{ccccc}
\hline $\begin{array}{c}\text { Dye conc. } \\
(\%)\end{array}$ & $\begin{array}{c}\text { Dry weight } \\
(\mathbf{m g} / \mathbf{5 0} \mathbf{~ m l})\end{array}$ & $\begin{array}{c}\text { Decolourization } \\
\text { percentage }(\%)\end{array}$ & $\begin{array}{c}\text { Dry weight } \\
(\mathbf{m g} / \mathbf{5 0} \mathbf{~ m l})\end{array}$ & $\begin{array}{c}\text { Pecolourization } \\
\text { percentage }(\boldsymbol{\%})\end{array}$ \\
\hline 0.00 & $470 \pm 3.90$ & 0.0 & $360 \pm 2.75$ & 0.00 \\
0.001 & $470 \pm 5.73$ & $75 \pm 0.10$ & $370 \pm 2.53$ & $54 \pm 0.22$ \\
0.002 & $480 \pm 6.80$ & $88 \pm 0.21$ & $380 \pm 2.47$ & $79 \pm 0.21$ \\
0.003 & $480 \pm 3.59$ & $91 \pm 0.31$ & $380 \pm 3.17$ & $75 \pm 0.13$ \\
0.004 & $480 \pm 4.37$ & $92 \pm 0.32$ & $360 \pm 4.22$ & $78 \pm 0.17$ \\
0.005 & $490 \pm 7.58$ & $92 \pm 0.20$ & $350 \pm 3.11$ & $81 \pm 0.12$ \\
0.01 & $510 \pm 5.29$ & $94 \pm 0.31$ & $350 \pm 5.11$ & $89 \pm 0.20$ \\
0.02 & $530 \pm 3.79$ & $94 \pm 0.33$ & $330 \pm 3.28$ & $86 \pm 0.30$ \\
\hline
\end{tabular}

\section{Effect of different incubation temperatures on dye decolorization}

A range of temperatures $\left(20-40^{\circ} \mathrm{C}\right)$ was used to study the effect of incubation temperature on direct blue dye decolorization. Results revealed that the decolorization of direct blue dye was most efficient at $30^{\circ} \mathrm{C}$ and $35^{\circ} \mathrm{C}$ with $97 \%$ and $80 \%$ of color reduction for Aspergillus flavus and Penicillium canescens, respectively. The decolorization percentage was low at lower and higher temperatures $\left(20,40^{\circ} \mathrm{C}\right)$ for both fungi. The growth was also affected by the incubation temperature (Table 2).

Table 2. Effect of different temperatures on dry weight and decolourization of direct blue dye by Aspergillus flavus and Penicillium canescens grown in Czapek's Dox liquid medium supplemented with $0.01 \%$ DB dye for 7 days. Data are expressed as mean values of three replicates \pm SE of the mean.

\begin{tabular}{llllc}
\hline \multirow{2}{*}{$\begin{array}{c}\text { Temperature } \\
\text { degree }\left({ }^{\circ} \mathbf{C}\right)\end{array}$} & $\begin{array}{c}\text { Dry mass } \\
(\mathbf{m g} / \mathbf{5 0} \mathbf{~ m l})\end{array}$ & $\begin{array}{c}\text { Decolorization } \\
\text { percentage }(\mathbf{\%})\end{array}$ & $\begin{array}{c}\text { Dry mass } \\
(\mathbf{m g} / \mathbf{5 0} \mathbf{~ m l})\end{array}$ & $\begin{array}{c}\text { Decolorization } \\
\text { percentage } \\
(\mathbf{\%})\end{array}$ \\
\hline 20 & $400 \pm 3.15$ & $78 \pm 0.73$ & $330 \pm 2.19$ & $62 \pm 0.37$ \\
25 & $420 \pm 3.11$ & $91 \pm 0.74$ & $380 \pm 3.27$ & $79 \pm 0.27$ \\
30 & $420 \pm 3.13$ & $97 \pm 0.45$ & $360 \pm 3.17$ & $85 \pm 0.35$ \\
35 & $420 \pm 2.75$ & $90 \pm 0.61$ & $360 \pm 3.15$ & $89 \pm 0.44$ \\
40 & $400 \pm 2.95$ & $88 \pm 0.52$ & $350 \pm 2.31$ & $83 \pm 0.12$ \\
\hline
\end{tabular}

\section{Effect of different incubation periods on decolorization activity of direct blue dye by Aspergillus flavus and Penicillium canescens}

The results presented in Table (3) indicated that decolorization activity reached the maximum value at 7 days of incubation for both fungi where it exhibited $97 \%$ and $92 \%$ for
A. flavus and $P$. canescens, respectively and gradually decreased above this incubation period where it reached $94 \%$ and $84 \%$ at 14 days for A. flavus and $P$. canescens respectively.

The final $\mathrm{pH}$ slightly decreased with A. flavus from 6 to 5.5 with increasing incubation periods whereas; with $P$. canescens it increased from 5.7 to 8.6 from the 4th to 14th day. The optimum growth was also obtained at 7 days of incubation period for both fungi.

\section{Effect of initial pH on dye decolorization}

Different initial $\mathrm{pH}$ values (3-8) in Czapek's Dox medium were used to determine their effects on decolorization of direct blue dye by both tested fungi.

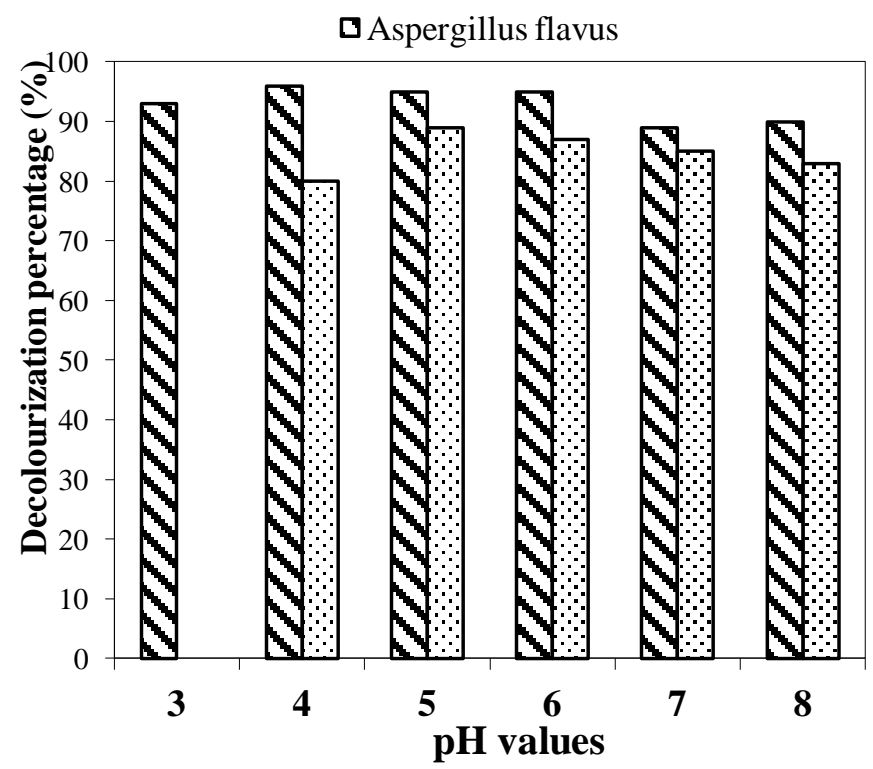

Fig. 5: Effect of different $\mathrm{pH}$ values on decolorization activity of direct blue dye by Aspergillus flavus and Penicillium canescens grown in Czapek's Dox liquid medium supplemented with $0.01 \% \mathrm{DB}$ dye at $30^{\circ} \mathrm{C}$ for 7 days.

There was a wide range of $\mathrm{pH}$ values for growth and dye decolorization by both fungi with optimum values at $\mathrm{pH} 4$ and $\mathrm{pH}$ 5 for $A$. flavus and $P$. canescens respectively where the decolorization percentages represented $96 \%$ and $89 \%$ respectively for both fungi (Fig. 5).

Table 3: Effect of different incubation periods on decolourization of direct blue dye by Aspergillus flavus and Penicillium canescens grown in Czapek's Dox liquid medium supplemented with $0.01 \% \mathrm{DB}$ dye at $30^{\circ} \mathrm{C}$. Data are expressed as mean values of three replicates $\pm \mathrm{SE}$ of the mean.

\begin{tabular}{|c|c|c|c|c|c|c|}
\hline \multirow{2}{*}{$\begin{array}{c}\text { Incubation period } \\
\text { (day) }\end{array}$} & \multicolumn{3}{|c|}{ Aspergillus flavus } & \multicolumn{3}{|c|}{ Penicillium canescens } \\
\hline & $\begin{array}{c}\text { Dry wt. (mg/50 } \\
\text { ml) }\end{array}$ & Final pH & $\begin{array}{l}\text { Decolorization } \\
\text { percentage }(\%)\end{array}$ & Dry wt. $(\mathrm{mg} / \mathbf{5 0} \mathrm{ml})$ & Final pH & $\begin{array}{l}\text { Decolorization } \\
\text { percentage }(\%)\end{array}$ \\
\hline 4 & $440 \pm 2.19$ & 6.06 & $91 \pm 0.11$ & $310 \pm 3.71$ & 5.74 & $84 \pm 0.11$ \\
\hline 7 & $470 \pm 1.70$ & 5.51 & $97 \pm 033$ & $400 \pm 4.17$ & 5.00 & $92 \pm 0.15$ \\
\hline 10 & $490 \pm 2.60$ & 5.78 & $95 \pm 0.32$ & $390 \pm 3.21$ & 7.98 & $89 \pm 0.23$ \\
\hline 14 & $490 \pm 2.71$ & 5.53 & $94 \pm 0.12$ & $300 \pm 3.35$ & 8.59 & $84 \pm 0.30$ \\
\hline
\end{tabular}


Effect of different carbon sources on decolorization activity of DB dye by $A$. flavus and $P$. canescens

The data of the effect of different carbon sources on decolorization value of DB dye are shown in Figure (6). A. flavus and $P$. canescens were characterized by their ability to use different carbon sources with high percentages of color reduction such as fructose, sucrose, glucose and maltose. Whereas, the growth of both organisms was low in the presence of lactose and subsequently low decolorization values were obtained.

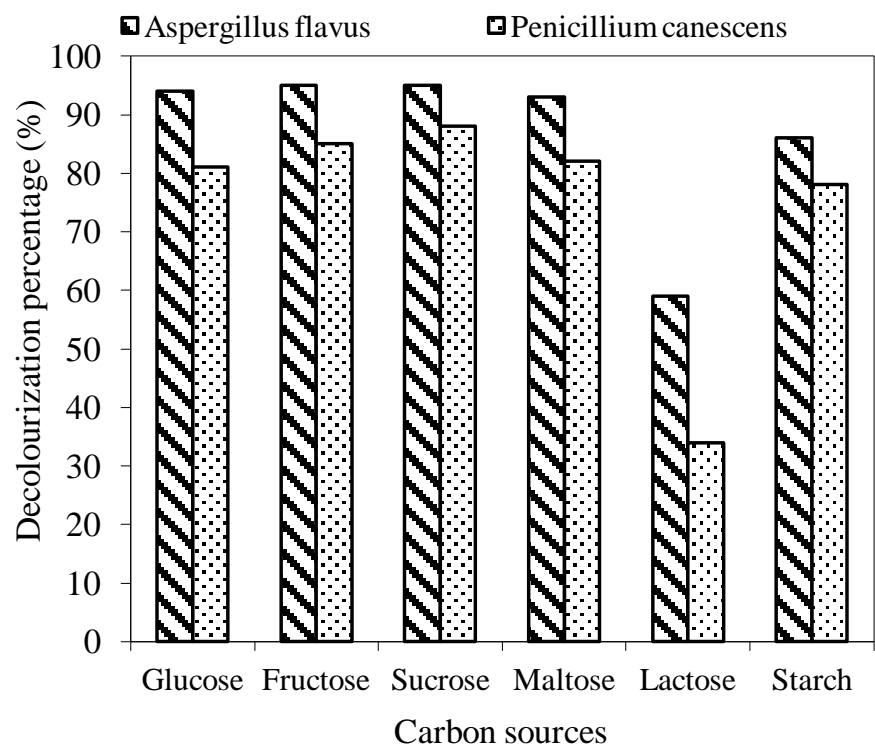

Fig. 6: Effect of different carbon sources on decolorization activity of direct blue dye by Aspergillus flavus and Penicillium canescens grown in Czapek's Dox liquid medium supplemented with $0.01 \%$ DB dye at $30^{\circ} \mathrm{C}$ for 7 days.

It was observed that the final $\mathrm{pH}$ in the growth medium of A. flavus remain in the acidic range with all utilized carbon source. While it shifted to the alkaline range with $P$. canescens with most utilized carbon source except with sucrose still in the acidic range.

Sucrose was the best carbon source utilized by both organisms for best decolorization percentage of direct blue dye. Whereas, the decolorization percentages reached $95 \%$ and $88 \%$ for A. flavus and $P$. canescens, respectively.

\section{Effect of different nitrogen sources on decolorization activity of direct blue dye}

The activity of growth and decolorization of direct blue dye by both tested fungi were evaluated in the presence of different nitrogen sources in the growth medium. The best growth and decolorization percentage were obtained in the presence of $\mathrm{NaNO}_{3}, \mathrm{NH}_{4} \mathrm{NO}_{3}$ and urea for both organisms and reach to approximately $96 \%$ for A. flavus and $91 \%$ for P. canescens (Fig. 7). It was also observed that the least decolorization percentage for direct blue dye was obtained in the presence of $\mathrm{KNO}_{3}$ in the growth medium for both fungi.

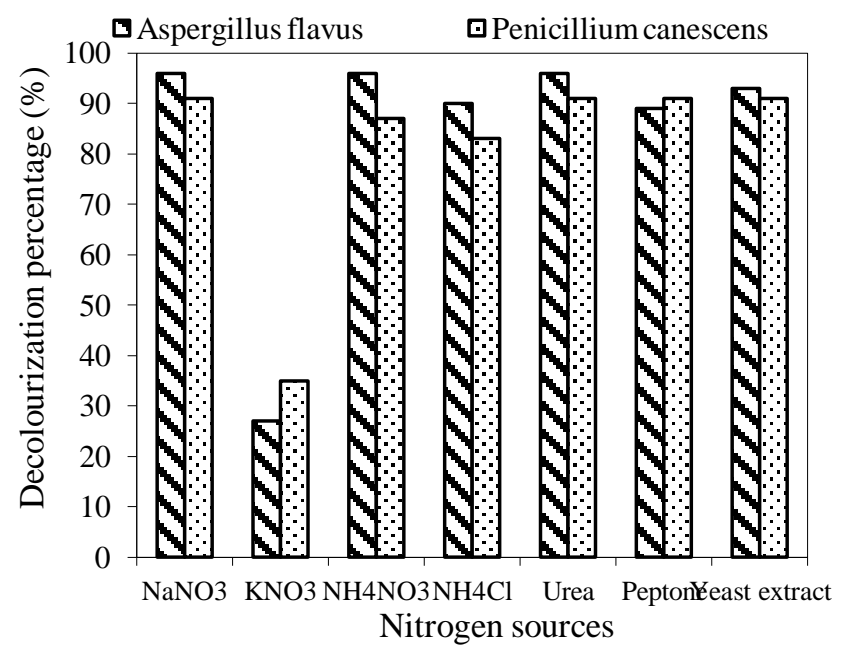

Fig. 7: Effect of different Nitrogen sources on decolorization of direct blue dye by Aspergillus flavus and Penicillium canescens grown in Czapek's Dox liquid medium supplemented with $0.01 \% \mathrm{DB}$ dye at $30^{\circ} \mathrm{C}$ for 7 days.

\section{Effect of some heavy metals on decolorization activity of direct blue dye}

A. flavus and $P$. canescens were grown in the presence of different heavy metals; $\mathrm{Cu}, \mathrm{Ca}, \mathrm{Ni}$ and $\mathrm{Co}(100 \mathrm{pm})$ in the growth medium as well as $0.01 \%$ direct blue dye to evaluate their effects on decolorization of direct blue dye. The results shown in Fig. (8) indicated that $\mathrm{Ca}, \mathrm{Ni}$, or Co slightly increased the decolorization values by A. flavus, where it was $(95.8 \%, 96.6 \%$ and $97.4 \%$, respectively compared to $95 \%$ at the control. While the presence of $\mathrm{Cu}^{+2}$ in the growth medium decreased the color reduction percentage to $(79 \%)$. On the other hand, the decolorization of direct blue dye by $P$. canescens decreased in the presence $\mathrm{Ca}, \mathrm{Ni}$ or $\mathrm{Co}$ in the growth medium, comparing with the control. Moreover, the growth and decolorization percentage were markedly decreased with $\mathrm{Cu}^{+2}$ where the decolorization reached to $30 \%$ comparing with $90 \%$ with the control.

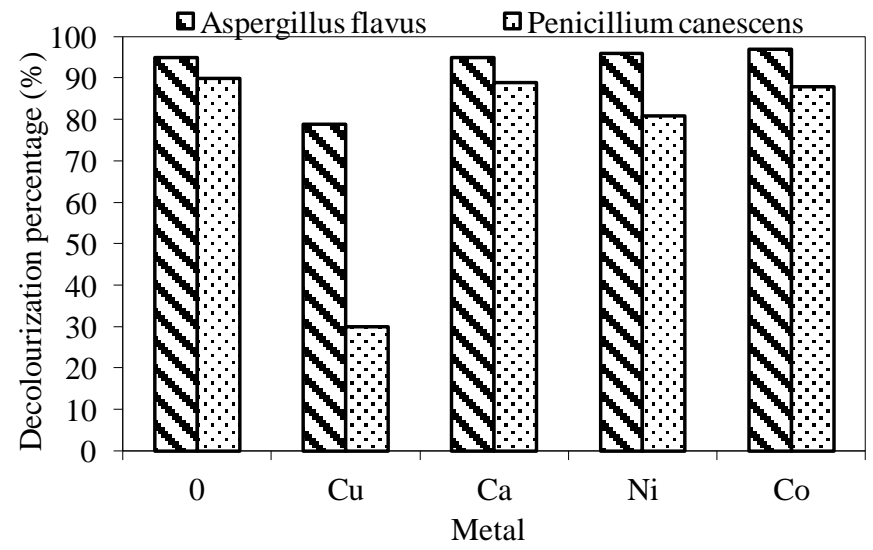

Fig. 8: Effect of heavy metals (100 ppm) on decolorization activity of direct blue dye by Aspergillus flavus and Penicillium canescens grown in Czapek's Dox liquid medium at $30^{\circ} \mathrm{C}$. 

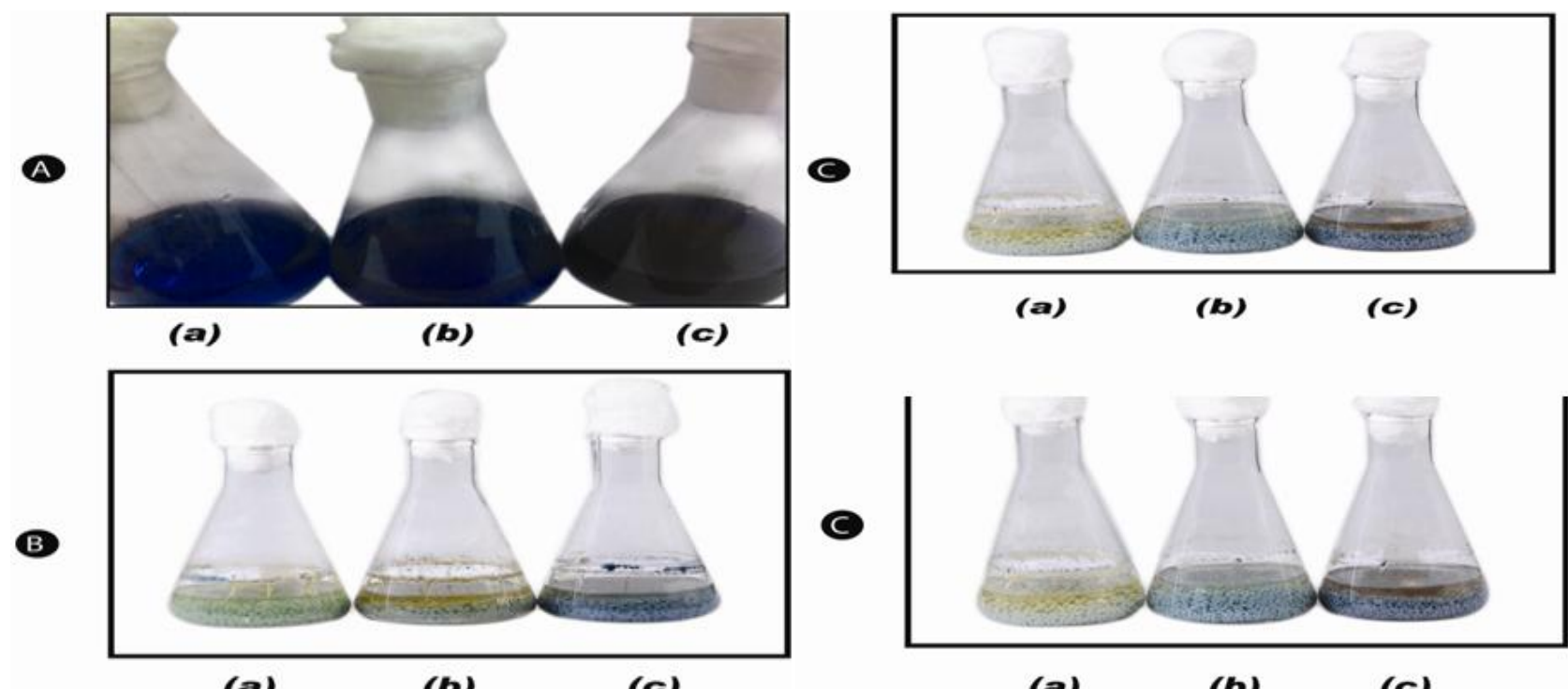

(b)

(c)

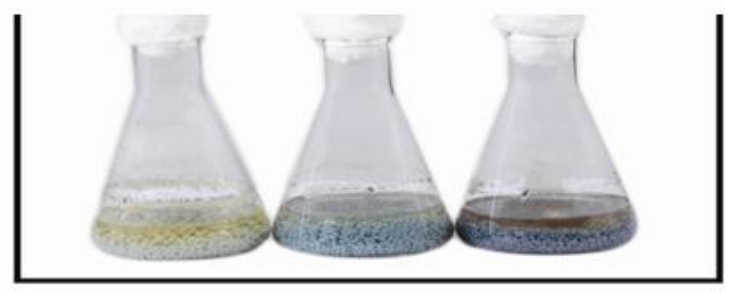

(a)

(b)

(c)

Fig. 9: Decolorization of direct blue dye (A) Control direct blue dye medium (B) Aspergillus flavus and (C) Penicillium canescens grown on Czapek's Dox liquid medium supplemented with different concentrations of Direct blue dye, (a) $(0.005 \% \mathrm{DB}),(\mathrm{b})(0.01 \% \mathrm{DB})$ and (c) $(0.02 \% \mathrm{DB})$.in shaking incubator for 7 days.

Table 4: Effect of static and shaking incubation on dry weight and decolorization activity of Aspergillus flavus and Penicillium canescens, in presence of $0.01 \%$ direct blue dye grown in Czapek's Dox liquid medium at $30^{\circ} \mathrm{C}$. Data are expressed as mean values of three replicates $\pm \mathrm{SE}$ of the mean.

\begin{tabular}{|c|c|c|c|c|c|c|}
\hline \multirow{3}{*}{ Fungal species } & \multicolumn{3}{|c|}{ Static } & \multicolumn{3}{|c|}{ Shaking } \\
\hline & \multicolumn{2}{|c|}{ Dry weight $(\mathrm{mg} / 50 \mathrm{ml})$} & \multirow{2}{*}{$\begin{array}{l}\text { Decolorization } \\
\text { percentage }(\%)\end{array}$} & \multicolumn{2}{|c|}{ Dry weight $(\mathrm{mg} / 50 \mathrm{ml})$} & \multirow{2}{*}{$\begin{array}{l}\text { Decolorization } \\
\text { percentage }(\%)\end{array}$} \\
\hline & $0.0 \%$ & $0.01 \%$ & & $0.0 \%$ & $0.01 \%$ & \\
\hline Aspergillus flavus & $440 \pm 4.11$ & $440 \pm 3.19$ & $97 \pm 0.31$ & $390 \pm 3.71$ & $420 \pm 4.11$ & $96 \pm 0.21$ \\
\hline Penicillium canescens & $370 \pm 5.11$ & $360 \pm 4.22$ & $93 \pm 0.22$ & $340 \pm 3.92$ & $300 \pm 3.75$ & $93 \pm 0.31$ \\
\hline
\end{tabular}

\section{Effect of static and shaking incubation on decolorization activity of $A$. flavus and $P$. canescens}

Direct blue dye was decolorized by both tested fungal species in a static and shaking incubation. It was found that no significant differences in the decolorization activity of both $A$. flavus and $P$. canescens were found when grown in static and shaking culture (Table 4 and Fig. 9).

\section{DISCUSSION}

The complex aromatic structure of the dyes is resistant to light, ozone and other degradative environmental conditions. Therefore, conventional treatment of wastewater from the textile industries remains ineffective. (Joshi et al., 2004). Up till now, scientists have been trying to develop a single and economical method for the treatment of dyes in the textile wastewater, but still it remains a big challenge (Dos Santos et al., 2007). The majority of research is directed towards biological treatment which provides reliable results, less sludge and more eco-friendly treatment (Ramalingam et al., 2010). In this study, six isolates were screened for maximum decolorization of direct blue dye as a preliminary step, two of which represented the highest isolates with decolorizing ability. The best decolorization value of direct blue dye by both $A$. flavus and $P$. canescens was obtained at the initial dye concentration of $0.01 \%$ and it decreased above this concentration which may be due to dye toxicity. This observation is similar to that obtained by Sumathi and Manju (2000), they reported that the reduction in the decolorization rates may be a result to toxicity of dye to bacteria and /or inadequate biomass concentration for the uptake of higher concentration of dye. Fetyan et al. (2016) found that Saccharomyces cervevisiae showed high efficiency to decolorize direct blue 71 reached to maximum activity $(100 \%)$ and this decolorization percentage decreased at the higher concentration above 200 ppm which may be due to the toxic effect at these higher concentrations for the yeast. Eichlerova et al. (2006) observed that there is a positive correlation between the growth rate and the decolorization ability, which is in agree with the results obtained. Singh and Singh (2010) also observed that the addition of dyes, Bromophenol blue and Congored in the culture medium (PDA) separately, inhibited the growth of Aspergillus flavus to various degrees, when compared to their respective controls. Similar results were also obtained by Kunjadia et al. (2012) who showed that the mycelial growth of Pleurotus ostreatus MTCC142 decreased with increasing of crystal violet dye concentration. Whereas, in this study the growth of Aspergillus flavus and Penicillium canescens increased with increasing concentrations of Direct blue dye in liquid media.

The decolorization activity and fungal growth of Aspergillus flavus and Penicillium canescens were found to increase with increasing incubation temperature for both 
organisms. Further increase in temperature above $35^{\circ} \mathrm{C}$ resulted in decrease in decolorization activity. This could be attributed to the loss of cell viability (Pearce et al., 2003) or might be due to the denaturation of ligninolytic enzymes. Similar results were obtained by Husseiny (2008) who found that the maximum degradation activity of Penicillium spp. to direct dye was at $35{ }^{\circ} \mathrm{C}$. Also Kaushik and Malik (2009) found that Aspergillus sp. which employed for the removal of Fast Red A dye was more efficient at $30{ }^{\circ} \mathrm{C}$. This also is in agreement with Parshetti et al. (2007) they found that $100 \%$ decolorization of Reactive Blue 25 (100 mg /L) by Aspergillus ochraceus occurred at $30^{\circ} \mathrm{C}$ for 7 days.

Concerning the effect of different incubation periods on fungal growth and decolorization of dye, it was found that maximal dye decolorization was obtained at 7 days of incubation period. After 7 days of incubation, the decolorization decreased gradually. This decrease might be due to the efflux mechanism of dye from the fungal cells to reduce dye toxicity. This was related to growth of A. flavus where the highest growth was also found at 7 days. While there was no relation between growth of $P$. canescens and decolorization of dye. The decreasing in the decolorization after 7 days and being not related to growth supports that the decolorization of Direct blue dye could be due to enzymatic biodegradation activity along with physical binding of dye on fungal biomass. These results are in harmony with those of Pazarlioglu et al. (2005) they reported that the bioremoval of Direct blue dye by Phanerochaete chrysosporum is due to enzymatic degradation while biosorption mechanism played a minor role. El-Sayeh (2010) also found that the maximal decolorization of Direct Violet dye by Aspergillus fumagatus obtained at the fourth day but decreased after that as well as the level of enzyme production. Ali et al. (2010) Also found that decolorization rate by brown-rot fungi for azo dyes was generally high at $96 \mathrm{~h}$. Moreover, it kept on declining with passing time in agitated fungal cultures. Machado et al. (2006) also reported this decreasing trend in decolorization with time, and explained that this phenomenon might be due to accumulation of dyes products that might have hindered growth and metabolizing potential of fungi.

With respect to the effect of $\mathrm{pH}$ value on the decolorization process, it was found that there was a wide range of $\mathrm{pH}$ values for tested fungi to grow and decolourize DB dye, with optimum value at $\mathrm{pH} 4$ and 5 for Aspergillus flavus and Penicillium canescens respectively. This indicates that the optimum $\mathrm{pH}$ for direct blue dye decolorization by these fungi lies in the acidic range. These results are in agree with Parshetti et al. (2007) who reported that the complete decolorization of Reactive Blue-25 (100 ppm) by Aspergillus ochraceus NCIM-1146 occurred at $\mathrm{pH}$ 5. However, $87 \%, 81 \%$ and $70 \%$ decolorization was obtained at $\mathrm{pH} \quad 3.7$ and 9 , respectively. This also in agree with results obtained by Husseiny (2008) who found that the maximum percentage of decolorization was at $\mathrm{pH} 4-4.5$ for Aspergillus niger and Penicillium sp. for Reactive Red and Direct Red dyes. On the other hand, neither growth nor decolorization was found at pH 3 in case of Penicillium canescens. Similar results were obtained by El-Sayeh (2010) who observed decreasing in the decolorization activity $(47 \%)$ at $\mathrm{pH} 3$ compared with (94\%) at $\mathrm{pH}$ 5.5 for Direct violet dye by Aspergillus fumigatus. These results suggest that acidic $\mathrm{pH}$ values may influence the stability of the enzymes. According to Tavares et al. (2006) laccase losses stability at $\mathrm{pH} 3$ whilst for $\mathrm{pH} 5$ no loss of enzyme activity is observed. These results were different in case of Aspergillus flavus where it has a wide range of $\mathrm{pH}$ (3-8) for good growth and decolorization with optimum value at $\mathrm{pH} 4$ which makes these isolates efficient for industrial applications and for the waste water treatment.

With regard to the effect of different carbon sources on decolorization process, it was found that the tested fungi were able to grow well and decolorize DB dye with all of the tested carbon sources except lactose where it was a poor carbon source. The results also indicated that sucrose was the best carbon source for dye decolorization. It was observed that when sucrose was used there was stability in $\mathrm{pH}$ value and high growth. The data showed that there is no significant difference between the decolorization percentages in case of fructose, glucose, sucrose and maltose and the starch comes later, finally, lactose was found to be the least source. Similar results were obtained by El-Sayeh (2010) when different carbon sources glucose, sucrose, fructose or maltose were used for growth of Aspergillus fumigatus and decolorization of Direct Violet dye. Also Miranda et al. (1996) reported that using sucrose at an initial concentration of $10 \mathrm{~g} / \mathrm{L}$ produced a maximum color removal of $69 \%$, while using molasses of $5 \mathrm{gm} / 1$ equivalent to sucrose only produced a color removal of $45 \%$ for Aspergillus niger. Also Parshetti et al. (2006) used molasses and sucrose as carbon sources for decolorization of Malachite Green (91\%) using Kocuria rosea MTCC 1532. Therefore the need to add carbon source depends on the organism and type of the dye to be treated.

Aspergillus flavus and Penicillium canescens exhibited high growth and decolorization percentage of DB dye with all utilized nitrogen sources except with $\mathrm{KNO}_{3}$. El-Sayeh (2010) also found that the highest fungal growth and ligninolytic enzymes production with the subsequent dye bioremoval were obtained in the peptone containing medium. In contrast, Parshetti et al. (2007) reported that presence of peptone in growth media during decolorization of Reactive Blue 25 by Aspergillus ochraceus showed an inhibitory effect.

Although, heavy metals are known as inhibitors of many enzymes belonging to both primary and secondary metabolic pathways. Copper has been reported to be a strong laccase inducer in several species, (Collins and Dobson, 1997). However, higher copper concentrations inhibited growth and notably decreased manganese peroxidase production, although they did not affect laccase secretion (Levin et al., 2002). Since the metal ions form a part of textile effluent, used to enhance the binding of the dye with the fiber, it was of interest to study the influence of some metal ions on dye decolorization activity by the tested fungi. The obtained results indicated that $\mathrm{Ca}, \mathrm{Ni}$ or $\mathrm{Co}$ raised the decolorization activity of Aspergillus flavus while, $\mathrm{Cu}^{+2}$ decreased 
this activity. These metals decreased the decolorization activity of Penicillium canescens especially $\mathrm{Cu}^{+2}$. On contrary, Murugesan et al. (2009) found that addition of $\mathrm{Cu}^{+2}$ ions up to $1 \mathrm{mM}$ enhanced the Ganoderma lucidum laccase activity and increased concentrations of $\mathrm{Cu}^{+2}$ ions resulted mainly in enhancement of decolorization process of Ramazol Black B and Ramzol Orange 16 reactive dyes.

With respect to the effect of shaking and stationary conditions on the decolorization process, it was found that the tested fungal isolates were efficient in dye removal either when incubated under shaking conditions or static ones, but the static culture generally was better than the shaking condition in both dye removal and fungal growth. Knapp et al. (1995) and Revankar and Lele (2007) found that the decolorization of dye in stationary cultures was mainly due to the sorption of the dyes on the fungal mat, while no adsorption of dye on fungal mycelium was seen in agitated culture and that indicates that the dye removal by the tested fungi was attributed to dye biodegradation and/or biosorption. However one or more of these mechanisms (biosorption, biodegradation or enzymatic mineralization) could be involved in colour removal, depending on the fungus used (Coulibaly et al., 2003). These results are in agreement with Husseiny (2008) who found that static conditions are more efficient than the shaking for both Aspergillus niger and Penicillium sp. on the decolorization of the reactive and direct dyebath solutions. These results are similar to those obtained by Daneshvar et al. (2007) using another type of microorganisms and can be discussed in terms of the high rate of the agitation decreases the fungal growth and the activities of some biological substances such as enzymes which play an important role in the decolorization of the dye (Faison and Kirk, 1985 and Ge et al., 2004). Shaking of cultures also inhibited the decolorization of Amaranth by Daedalea flavida (Rani et al., 2012). On the contrary, El-Sayeh (2010) found that direct violet dye decolourization by Aspergillus fumigatus was more efficient in agitated cultures as compared in stationary culture and these results agree with those of Yesilada et al. (2002) and Parshetti et al. (2007) who reported that the shaking conditions are better for dye decolorization as compared to static conditions. The increased activity in dye decolorization could be attributed to the increased transfer of oxygen and distribution of nutrient.

Generally, the mechanism of fungal dye decolorization and degradation is either biodegradation and biosorption by living cells or biosorption by dead cells (Fu and Viraraghavan, 2001) which involves physico-chemical interaction such as adsorption, deposition, and ion-exchange (Wesenberg et al., 2003).

\section{CONCLUSION}

Fungi decolorization of direct blue dye can be achieved by treating with (Aspergillus flavus, Aspergillus niger, Penicillium canescens, Penicillium crustosum, Penicillium sp., and Fusarium $s p$ ). Among the isolates two of fungal isolates (Aspergillus flavus and Penicillium canescens) were capable of removing the highest percent of dye color after 6 days incubation. This study concluded that the bioremediation process is ideal to reduce dyes toxicity with low-cost and environmentally friendly.

\section{Financial support and sponsorship: Nil.}

Conflict of Interests: There are no conflicts of interest.

\section{REFERENCES}

Ali N, Abdul Hameed, Ahmed S. Role of brown-rot fungi in the bioremoval of azo dyes under different conditions, Braz. J. Microbiol, 2010; 41: 907- 915 .

Casieri L, Varese G, Anastasi A, Prigione V, Svobodova K, Marchisio VF, Novotny C.. Decolortization and detoxification of reactive industrial dyes by immobilized fungi Trametes pubescens and Pleurotus ostretus. Folia Microbiol, 2008; 53:44-52.

Collins PJ, Dobson A. Regulation of laccase gene transcription in Trametes versicolor, Appl. Environ. Microbiol, 1997; 63:3444-3450.

Coulibaly L, Gourene G, Agathos, S. Utilization of fungi for biotreatment of raw wastewaters, Afr. J. Biotechnol. 2003; 2:620-630.

Chivukula M, Renganathan V. Phenolic azo dye oxidation by laccase from Pyricularia oryzae, App. Environ. Microbiol. 1995; 61: 43744377.

Dhaneshvar N, Ayazloo M, Khatae A, Pourhassan M. Biological decolourization of dye solution containing malachite green by microalga Cosmarium sp. Bioresour Technol, 2007; 29:1-7.

Dos Santos A, Cervantes F, Van Lier J. Review paper on current technologies for decolourisation of textile wastewaters: perspective for anaerobic biotechnology. Bioresource Technol, 2007; 98: 2369-2385.

Eichlerova I, Homolka, Nerud F. Synthetic dye decolorization capacity of white rot fungus Dichomitus squalens, Bioresour. Technol, 2006; 97:2153-2159.

El-Sayeh I. Fungal Biodegradation of Textile Dyes, M. Sc. Thesis. Science Faculty, Al-Azhar University (Girls Branch) Egypt, 2010.

Faison D, Kirk T. Factors involved in the regulation of ligninase activity in Phanerochaete chrysosporium. Appl. Environ. Microbiol, 1985; 49: 299-304.

Fetyan NAH, Abdelazeiz AZ, Ismail IM, Shaban SA. Oxidative decolorization of direct blue 71 Azo dye by Saccharomyces cervisiae catalyzed by nano zero-valent iron. Annual Research \& Review in Biology, 2016; 11(11): 1-12.

Forgacs E, Cserhati T, Oros G. Removal of synthetic dyes from wastewaters, a review. Environ Int, 2004; 30: 953-971.

$\mathrm{Fu}$ Y, Viraraghavan T. Fungal decolorization of dye waste waters, a review. Bioresour Technol, 2001; 79: 251-262.

Ge Y, Yan L, Qing K. Effect of environment factors on dye decolourization by Penicillium sordida AATCC 90872 in an aerated reactor. Process Biochem, 2004 39: 1401-1405.

Hao J, Kim H, Chang P. Decolourization of wastewater. Crit Rev Environ Sci Technol, 2000; 30: 499-505.

Husseniy M. Biodegradation of reactive and direct dyes using Egyptian isolates. J. Appl Sci Res, 2008; 4:599-606.

Joshi M, Bansal R, Purwar R. Colour removal from textile effluents. Ind J Fibre Textile Res, 2004; 29:239-259.

Kaushik P, Malik A. Effect of the nutrient composition on dye decolourization and extra cellular enzyme production by Lentinus edodes on solid meium. Enzyme Microbial Technol, 2009; 30:381-3867.

Knapp S, Newby S, Reece P. Decolorization of dyes by wood rotting basidiomycete fungi. Enzyme Microbial Technol, 1995; 17: 664668.

Kunjadia P, Patel FD, Nagee A, Mukhopadhyaya NP, Dave SG. Crystal Violet ( Triphenyl Methane Dye ) Decolourization potential of Pleurotus ostreatus (MTCC 142). Bio Resources, 2012; 7: 1189-1199.

Levin L, Forichiassin F, Ramos M. Copper induction of ligninmodifying enzymes in the white-rot fungus Trametes trogii. Mycologia, 2002; 94:377-383. 
Machado G, Matheus R, Monteiro R, Bononi R. Biodegradation of pentachlorophenol by tropical basidiomycetes in soils contaminated with industrial residues. W. J. Microbiol. Biotechnol, 2005; 21:297-301.

Machado G, Compart A, Morais O, Rosa H, Santos H. Biodegradation of reactive textile dyes by Basidiomycetous fungi from Brazilian ecosystem, Brazil. J. Microbiol, 2006; 37:481-487.

Miranda P, Benito G, Cristobal S, Nieto H. Color elimination from molasses wastewater by Aspergillus niger. Bioresour. Technol, 1996; 57:299-235.

Murugesan K, Kim M, Jeon R, Chang S. Effect of metal ions on reactive dye decolorization by laccases from Ganoderma lucidum. J. Hazard Mater, 2009; 168:523-529.

Parshetti GK, Kalme D, Gomare S, Govindwar P. Biodegradation of Reactive blue-25 by Aspergillus ochraceus NCIM1146. J. Bioresour Technol, 2007; 98: 3638-3642.

Parshetti G, Kalme S, Saratale G, Govindwar S. Biodegradation of Malachite Green by Kocuria rosea MTCC 1532. Acta. Chimica Slovenica, 2006; 53:492-498.

Pazarlioglu K, Urek O, Ergun F. Biodecolourization of Direct blue 15 by immobilized Phanerochaete chrysosporium. Process Biochem, 2005; 40:1923-1929.

Pearce I, Lioyd R, Guthrie T. The Removal of Colour from Textile Wastewater using Whole Bacterial Cells. A Review. Dyes and Pigments, 2003; 58: 179-196.

Ponraj M, Jamunarani P, Zambare V. Isolation and Optimization of Culture conditions for Decolorization of True Blue Using Dye Decolorizing fungi, Asian J. Exp. Biol. Sci., 2011; 2: 270-277.

Ramalingam N, Shanmugaprakash M. Decolorization of textile dyes by Aspergillus tamari, mixed fungal culture and Penicillium purpurogenum. J. Sci. Ind. Res., 2010; 69:151-153.

Rani Ch, Jana KA, Bansal A. Potential of different white rot fungi to decolorize textile azo dyes in the absence of external carbon source, Envir. Technol, 2012; 33(8): 887-896.

Revankar S, Lele S. Synthetic dye decolourization by white rot fungus, Ganoderma sp. WR-1. Bioresour. Technol, 200798: 775-780.

Robinson T, Chandran B, Nigam P. Studies on the production of enzymes by white-rot fungi for the decolorization of textile dyes, Enzyme Microb. Technol, 2001; 29:575-579.

Sathiya P, Periyar S, Sasikalaveni A, Murugesan K, Kalaichelvan T. Decolorization of textile dyes and their effluents using white rot fungi. Afr. J. Biotechnol, 2007; 6(4):424-429.

Singh L, Singh P. Biodegradation of Textile Dyes, Bromophenol Blue and Congored by fungus Aspergillus flavus, Environ. We Int. J. Sci. Tech, 2010; 5: 235-242.
Shinkafi MS, Mohammed IU, Audu AA. The potentials of white-rot fungi to decolorizing azo dyes and organic components of textile effluents. European Journal of Biotechnology and Bioscience, 2015; 3(10):52-57

Shrivastava V. Advances in Applied Science Research, 2011; 2:pp280.

Sumathi S, Manju B. Uptake of reactive textile dyes by Aspergillus foetidus. Enzyme Microb, Technol, 2000; 27: 347-355.

Tavares M, Coelho Z., Agapito M, Coutinho P, Xavier B. Optimization and modeling of laccase production by Trametes versicolor in a bioreactor using statistical experimental design. Appl. Biochem. Biotechnol, 2006; 134:233-248.

Trinci P. Influence of the width of the peripheral growth zone on the radial growth rate of fungal colonies on solid media. J Gen Microbiol, 1971; 67:752-759.

Warcup $\mathrm{H}$. The soil-plate method for isolation of fungi from soil. Nature, 1950; 166:117-118.

Wesenberg D, Kyriakides I, Agathos N. White-rot fungi and their enzymes for the treatment of industrial dye effluents. Biotechnology Advances, 2003; 22:161-187.

Yang P, Shi W, Wang H. Liu H. Screening of freshwater for decolorizing multiple synthetic dyes Brazilian Journal of Microbiolog, 2016;47(4):828-834.

Yesilada O, Cing S, Asma D. Decolourization of the textile dye Astrazon Red FBL by Funalia trogii pellets, 2002; 81: 155-157.

Zollinger H. Color chemistry: Synthesis, Properties and Applications of organic Dyes and Pigments, second ed. VHC Publishers, New York, 1991.

Zollinger H. Color Chemistry. Syntheses, Properties and Applications of Organic Dyes and Pigments, Third ed., Verlag Helvetica Chimica, 2003.

\section{How to cite this article:}

Hefnawy MA, Gharieb MM, Shaaban MT, Soliman AM. Optimization of Culture Condition for Enhanced Decolorization of Direct blue Dye by Aspergillus flavus and Penicillium canescens. J App Pharm Sci, 2017; 7 (02): 083-092. 